\title{
A COLD COMPLEX CHEMISTRY TOWARD THE LOW-MASS PROTOSTAR B1-b: EVIDENCE FOR COMPLEX MOLECULE PRODUCTION IN ICES*
}

\author{
Karin I. ÖberG ${ }^{1,2,5}$, SAndrine Bottinelli ${ }^{3}$, Jes K. Jørgensen ${ }^{4}$, And Ewine F. VAn DishoecK ${ }^{2,6}$ \\ ${ }^{1}$ Harvard-Smithsonian Center for Astrophysics, MS 42, 60 Garden Street, Cambridge, MA 02138, USA \\ ${ }^{2}$ Leiden Observatory, Leiden Sterrewacht, P.O. Box 9513, 2300 RA Leiden, The Netherlands \\ ${ }^{3}$ Centre d'Etude Spatiale des Rayonnements, 9 avenue du Colonel Roche, BP 4346, 31028 Toulouse Cedex 4, France \\ ${ }^{4}$ Centre for Star and Planet Formation, Natural History Museum of Denmark, University of Copenhagen, Øster Voldgade 5-7, 1350 Copenhagen K., Denmark \\ Received 2010 February 20; accepted 2010 April 28; published 2010 May 21
}

\begin{abstract}
Gas-phase complex organic molecules have been detected toward a range of high- and low-mass star-forming regions at abundances which cannot be explained by any known gas-phase chemistry. Recent laboratory experiments show that UV irradiation of $\mathrm{CH}_{3} \mathrm{OH}$-rich ices may be an important mechanism for producing complex molecules and releasing them into the gas phase. To test this ice formation scenario, we mapped the B1-b dust core and nearby protostar in $\mathrm{CH}_{3} \mathrm{OH}$ gas using the IRAM $30 \mathrm{~m}$ telescope to identify locations of efficient non-thermal ice desorption. We find three $\mathrm{CH}_{3} \mathrm{OH}$ abundance peaks tracing two outflows and a quiescent region on the side of the core facing the protostar. The $\mathrm{CH}_{3} \mathrm{OH}$ gas has a rotational temperature of $\sim 10 \mathrm{~K}$ at all locations. The quiescent $\mathrm{CH}_{3} \mathrm{OH}$ abundance peak and one outflow position were searched for complex molecules. Narrow, $0.6-0.8 \mathrm{~km} \mathrm{~s}^{-1}$ wide, $\mathrm{HCOOCH}_{3}$ and $\mathrm{CH}_{3} \mathrm{CHO}$ lines originating in cold gas are clearly detected, $\mathrm{CH}_{3} \mathrm{OCH}_{3}$ is tentatively detected, and $\mathrm{C}_{2} \mathrm{H}_{5} \mathrm{OH}$ and $\mathrm{HOCH}_{2} \mathrm{CHO}$ are undetected toward the quiescent core, while no complex molecular lines were found toward the outflow. The core abundances with respect to $\mathrm{CH}_{3} \mathrm{OH}$ are $\sim 2.3 \%$ and $1.1 \%$ for $\mathrm{HCOOCH}_{3}$ and $\mathrm{CH}_{3} \mathrm{CHO}$, respectively, and the upper limits are $0.7 \%-1.1 \%$, which is similar to most other low-mass sources. The observed complex molecule characteristics toward B1-b and the pre-dominance of HCO-bearing species suggests a cold ice (below $25 \mathrm{~K}$, the sublimation temperature of $\mathrm{CO}$ ) formation pathway followed by non-thermal desorption through, e.g., UV photons traveling through outflow cavities. The observed complex gas composition together with the lack of any evidence of warm gas-phase chemistry provides clear evidence of efficient complex molecule formation in cold interstellar ices.
\end{abstract}

Key words: astrochemistry - astrobiology - ISM: abundances - ISM: molecules

Online-only material: color figures

\section{INTRODUCTION}

Complex organic molecules have been detected toward a range of astrophysical environments, including low-mass protostars (van Dishoeck et al. 1995; Cazaux et al. 2003; Bottinelli et al. 2007); however, the origins of these complex molecules as well as their fates are uncertain. Commonly suggested formation routes for the detected molecules include various gasphase reactions starting with thermally evaporated $\mathrm{CH}_{3} \mathrm{OH}$ ice, atom-addition reactions on dust grains, and UV- and cosmicray-induced chemistry in the icy grain mantles that form during the pre-stellar stages (Charnley et al. 1992; Nomura \& Millar 2004; Herbst \& van Dishoeck 2009, for a review). The focus is currently on an ice formation pathway (e.g., Garrod \& Herbst 2006; Garrod et al. 2008) because of the failures of gas-phase chemistry to explain the observed abundances of some of the most common complex molecules toward low-mass protostars, especially $\mathrm{HCOOCH}_{3}$.

Recent experiments on the photochemistry of $\mathrm{CH}_{3} \mathrm{OH}$-rich ices have shown that (1) UV irradiation of $\mathrm{CH}_{3} \mathrm{OH}$ ices at $20-70 \mathrm{~K}$ result in the production of large amounts of the complex molecules observed around protostars and (2) the chemistry has a product branching ratio which is temperature and ice composition dependent (Öberg et al. 2009b). A key result is

\footnotetext{
* Based on observations carried out with the IRAM $30 \mathrm{~m}$ telescope. IRAM is supported by INSU/CNRS (France), MPG (Germany), and IGN (Spain).

5 Hubble fellow.

6 Also at Max-Planck Institute für Extraterrestrische Physik, Giessenbachstr. 1, 85748 Garching, Germany.
}

that $\mathrm{HCOOCH}_{3}$ and other $\mathrm{HCO}-\mathrm{X}$ ices are only abundantly produced in $\mathrm{CO}: \mathrm{CH}_{3} \mathrm{OH}$ mixtures. A similar result has been reported for proton-bombarded $\mathrm{CH}_{3} \mathrm{OH}$ and $\mathrm{CH}_{3} \mathrm{OH}: \mathrm{CO}$ ices (Bennett \& Kaiser 2007). $\mathrm{CO}: \mathrm{CH}_{3} \mathrm{OH}$ ice mixtures are probably common since $\mathrm{CH}_{3} \mathrm{OH}$ forms from hydrogenation of $\mathrm{CO}$ (e.g., Watanabe et al. 2003; Cuppen et al. 2009). CO evaporates at $17-25 \mathrm{~K}$ on astrophysical timescales (Bisschop et al. 2006), and thus HCO-X ices will mainly form in cold, UV-exposed ices. At higher temperatures, closer to the protostar, UV irradiation of the remaining pure $\mathrm{CH}_{3} \mathrm{OH}$ ice will instead favor the production of $\mathrm{C}_{2} \mathrm{H}_{5} \mathrm{OH}, \mathrm{CH}_{3} \mathrm{OCH}_{3}$, and $\left(\mathrm{CH}_{2} \mathrm{OH}\right)_{2}$.

In light of this proposed formation scenario, protostars rich in $\mathrm{CH}_{3} \mathrm{OH}$ ice are natural targets when searching for complex molecule sources. The low-mass protostar B1-b is such a source. From previous SCUBA and $3 \mathrm{~mm}$ continuum maps, B1-b consists of two cores B1-bN and B1-bS separated by 20" (Hirano et al. 1999). The cores are similar with $T_{\text {dust }} \sim 18 \mathrm{~K}$, $M=1.6-1.8 M_{\odot}$, and $L_{\mathrm{bol}}=2.6-3.1 L_{\odot}$. The Spitzer Space Telescope only observed one protostar, to the southwest of the B1-bS dust core at 03:33:20.34, +31:07:21.4 (J2000), but it was still named B1-b-to avoid confusion it will be referred to as the "protostar" position. From the Spitzer c $2 d$ (from molecular cores to planet-forming disks) ice survey the $\mathrm{B} 1-\mathrm{b}$ protostar has a $\mathrm{CH}_{3} \mathrm{OH}$ ice abundance of $11 \%$ with respect to $\mathrm{H}_{2} \mathrm{O}$ ice (Boogert et al. 2008), corresponding to $\sim 5 \times 10^{-6}$ with respect to $\mathrm{H}_{2}$. The fractional abundance of $\mathrm{H}^{13} \mathrm{CO}^{+}$decreases by a factor of 5 toward the SCUBA core, indicative of CO freezeout (Hirano et al. 1999). An HCO-dominated complex chemistry is thus expected where the ice is exposed to UV radiation. 
Table 1

Observational Parameters

\begin{tabular}{lcccc}
\hline \hline \multicolumn{4}{c}{ Positions and $\mathrm{CH}_{3} \mathrm{OH}$ observations with HERA } \\
\hline Name & R.A. (J2000) & Decl. (J2000) & rms (mK) & $\delta V\left(\mathrm{~km} \mathrm{~s}^{-1}\right)$ \\
\hline "Core" & $03: 33: 20.80$ & $31: 07: 40.0$ & 92 & 0.39 \\
"Outflow" & $03: 33: 21.90$ & $31: 07: 22.0$ & 65 & 0.77 \\
"Protostar" & $03: 33: 20.34$ & $31: 07: 21.4$ & 92 & 0.39 \\
\hline
\end{tabular}

\begin{tabular}{|c|c|c|c|c|c|c|}
\hline \multicolumn{7}{|c|}{ Complex molecule observations with EMIR } \\
\hline \multirow[t]{2}{*}{ Setting } & \multirow[t]{2}{*}{ Receiver } & \multirow[t]{2}{*}{ Frequency Band $(\mathrm{GHz})$} & \multicolumn{2}{|c|}{$\mathrm{rms}(\mathrm{mK})$} & \multicolumn{2}{|c|}{$\delta V\left(\mathrm{~km} \mathrm{~s}^{-1}\right)$} \\
\hline & & & 'Core"' & "Outflow" & "Core" & "Outflow" \\
\hline \multirow[t]{2}{*}{1} & E90 & $88.81-88.93$ & 5.4 & 2.0 & 0.26 & 2.1 \\
\hline & E150 & $146.84-146.96$ & 5.5 & 2.2 & 0.32 & 1.3 \\
\hline \multirow[t]{2}{*}{2} & E90 & $115.46-115.58$ & 14.6 & 9.9 & 0.41 & 1.6 \\
\hline & E150 & $146.93-147.05$ & 4.6 & 3.9 & 0.32 & 1.3 \\
\hline 3 & E150 & $130.82-130.94$ & 8.4 & $\cdots$ & 0.18 & $\ldots$ \\
\hline
\end{tabular}

Notes.

a The "core" is the quiescent $\mathrm{CH}_{3} \mathrm{OH}$ maximum $\sim 10$ offset from the SCUBA core and the "protostar" is the source discovered by Spitzer.

The B1-b region is complicated by a number of outflows, which may enhance the UV field through shocks and open cavities through which stellar UV photons can escape (Jørgensen et al. 2006; Walawender et al. 2009; Hiramatsu et al. 2010). The outflow of most interest to this study runs in the southwest direction from the B1-b protostar, though it is not known whether B1-b is its source or just happens to lie in its path. The outflow is not observed northeast of the B1-b protostar, where the B1-b SCUBA core is situated. It is therefore unclear whether the outflow terminates at the protostar or continues into the core, hidden from view. If it does penetrate into the SCUBA core, this may increase the UV flux in the region by orders of magnitude, enhancing both the UV photochemistry and photodesorption of ices.

The latter is important, since once formed, the complex molecules must be (partly) released into the gas phase to be observable at millimeter wavelengths. The second reason for targeting B1-b is the detection of a large $\mathrm{CH}_{3} \mathrm{OH}$ gas-phase column density of $\sim(2.3-2.5) \times 10^{14} \mathrm{~cm}^{-2}$ toward the protostar (Öberg et al. 2009a; Hiramatsu et al. 2010) and thus ice evaporation. The narrow line width and low excitation temperature of the observed $\mathrm{CH}_{3} \mathrm{OH}$ suggest non-thermal ice evaporation - the abundances are consistent with UV photodesorption. Assuming that complex ice chemistry products desorb non-thermally at an efficiency similar to $\mathrm{CH}_{3} \mathrm{OH}\left(\sim 10^{-3}\right.$ molecules per incident UV photon; Öberg et al. 2009b), the protostellar environment should contain a cold gas-phase fingerprint of the complex ice composition; B1-b may offer the first possibility to observe the earliest stages of complex molecule formation, untainted by either warm ice chemistry or gas-phase processing.

Addressing these predictions, we present Institut de RadioAstronomie Millimétrique (IRAM) $30 \mathrm{~m}$ telescope observations of an $80^{\prime \prime} \times 80^{\prime \prime} \mathrm{CH}_{3} \mathrm{OH}$ map of the B1-b protostellar envelope and nearby dust cores, followed by a search for $\mathrm{HCOOCH}_{3}$, $\mathrm{CH}_{3} \mathrm{CHO}, \mathrm{CH}_{3} \mathrm{OCH}_{3}, \mathrm{C}_{2} \mathrm{H}_{5} \mathrm{OH}$, and $\mathrm{HOCH}_{2} \mathrm{CHO}$ toward two of the identified $\mathrm{CH}_{3} \mathrm{OH}$ peaks. The $\mathrm{CH}_{3} \mathrm{OH}$ gas abundances and the complex abundances and upper limits with respect to $\mathrm{CH}_{3} \mathrm{OH}$ are then discussed in terms of different ice desorption mechanisms and complex molecule formation scenarios. The results are finally compared with complex molecule observations toward other low-mass protostars and outflows.

\section{OBSERVATIONS AND DATA REDUCTION}

The B1-b protostellar envelope and the nearby SCUBA cores were mapped in three $\mathrm{CH}_{3} \mathrm{OH}$ transitions in 2009 February using the HEterodyne Receiver Array (HERA; Schuster et al. 2004) on the IRAM $30 \mathrm{~m}$ telescope together with the VESPA autocorrelator back end (Tables 1 and 2). The $80^{\prime \prime} \times 80^{\prime \prime}$ map is centered on R.A. 03:33:21.3 and decl. 31:07:36.7 (J2000), the estimated midpoint between B1b-S and B1b-N (Hirano et al. 1999). VESPA was used with a $320 \mathrm{kHz}$ channel spacing resulting in a velocity resolution of $0.78 \mathrm{~km} \mathrm{~s}^{-1}$ (channel spacing $\delta \mathrm{V}$ of $\sim 0.39 \mathrm{~km} \mathrm{~s}^{-1}$ ) at $242 \mathrm{GHz}$. Observations were carried out through two separate undersampled ( $8^{\prime \prime}$ spacing) raster maps using beam switching with a throw of $200^{\prime \prime}$ in azimuth. The two maps were offset by $+4^{\prime \prime},+4^{\prime \prime}$ and the combination of the two maps thus results in a single over-Nyquist-sampled map-the half-power beamwidth of the $30 \mathrm{~m}$ telescope at $242 \mathrm{GHz}$ is $\sim 10^{\prime \prime}$. The rms is $\sim 50 \mathrm{mK}$ in the first map and $\sim 130 \mathrm{mK}$ in the second map in a $0.39 \mathrm{~km} \mathrm{~s}^{-1}$ channel. The average rms over the entire map was estimated to $\sim 90 \mathrm{mK}$. The system temperature varied between 600 and $1200 \mathrm{~K}$.

The second set of observations aimed at detecting complex molecules was carried out in 2009 June with the IRAM $30 \mathrm{~m}$ telescope, using the new Eight MIxer Receiver (EMIR) (Table 1). The positions used for pointing correspond to the $\mathrm{CH}_{3} \mathrm{OH}$ maximum toward the center of the SCUBA core at 03:33:20.80, 31:07:40.0 (J2000), termed the "core" position, and a local maximum at 03:33:21.90, 31:07:22.0 (J2000) termed the "outflow" position. The targeted lines are listed in Table 3 and the frequencies are taken from the JPL molecular database and the Cologne Database for Molecular Spectroscopy (Müller et al. 2001). The focus is on lines with low excitation energies $(15-100 \mathrm{~K})$ because of the previously discovered low excitation temperature of $\mathrm{CH}_{3} \mathrm{OH}$ toward the same source. The chosen settings contain at least two lines for $\mathrm{HCOOCH}_{3}, \mathrm{CH}_{3} \mathrm{CHO}$, $\mathrm{CH}_{3} \mathrm{OCH}_{3}$, and $\mathrm{C}_{2} \mathrm{H}_{5} \mathrm{OH}$ (and additional $\mathrm{HOCH}_{2} \mathrm{CHO}$ and $\mathrm{C}_{2} \mathrm{H}_{5} \mathrm{CN}$ lines) to allow us to constrain the excitation temperatures of any detected species. The observations were carried out using three different receiver settings, each including a combination of the EMIR 90 and $150 \mathrm{GHz}$ receivers (Table 1). At these wavelengths, the beam sizes are $\sim 27^{\prime \prime}$ and $19^{\prime \prime}$, 
Table 2

Observed $\mathrm{CH}_{3} \mathrm{OH}$ Lines with $1 \sigma$ Uncertainties in Brackets

\begin{tabular}{|c|c|c|c|c|c|c|c|}
\hline Position & Transition & $\begin{array}{c}\text { Frequency } \\
(\mathrm{GHz})\end{array}$ & $\begin{array}{c}E_{\mathrm{low}} \\
\left(\mathrm{cm}^{-1}\right)\end{array}$ & $\begin{array}{c}\text { FWHM } \\
\left(\mathrm{km} \mathrm{s}^{-1}\right)\end{array}$ & $\begin{array}{l}\int T d V 10^{\prime \prime} \\
\left(\mathrm{K} \mathrm{km} \mathrm{s}^{-1}\right)\end{array}$ & $\begin{array}{l}\int T d V 19^{\prime \prime} \\
\left(\mathrm{K} \mathrm{km} \mathrm{s}^{-1}\right)\end{array}$ & $\begin{array}{l}\int T d V 27^{\prime \prime} \\
\left(\mathrm{K} \mathrm{km} \mathrm{s}^{-1}\right)\end{array}$ \\
\hline \multirow[t]{3}{*}{ "Core" } & $\mathrm{A}^{+} 5_{05}-4_{04}$ & 241.7914 & 16.1 & $1.2[0.1]$ & $2.8[0.6]$ & $1.5[0.3]$ & $1.2[0.3]$ \\
\hline & $E^{-} 5_{15}-4_{14}$ & 241.7672 & 20.0 & $1.3[0.1]$ & $2.2[0.4]$ & $1.2[0.2]$ & $1.1[0.2]$ \\
\hline & $E^{-} 5_{05}-4_{04}$ & 241.7002 & 25.3 & $2.4[0.5]$ & $0.5[0.1]$ & $0.2[0.1]$ & $0.2[0.1]$ \\
\hline \multirow[t]{3}{*}{ “Outflow” } & $\mathrm{A}^{+} 5_{05}-4_{04}$ & 241.7914 & 16.1 & $4.0[0.2]$ & $3.3[0.7]$ & $1.9[0.4]$ & $1.4[0.4]$ \\
\hline & $E^{-5} 5_{15}-4_{14}$ & 241.7672 & 20.0 & $4.4[0.3]$ & $2.8[0.5]$ & $1.6[0.3]$ & $1.2[0.3]$ \\
\hline & $E^{-} 5_{05}-4_{04}$ & 241.7002 & 25.3 & $5.7[1.6]$ & $0.5[0.1]$ & $0.2[0.1]$ & $0.2[0.1]$ \\
\hline \multirow[t]{3}{*}{ "Protostar" } & $\mathrm{A}^{+} 5_{05}-4_{04}$ & 241.7914 & 16.1 & $1.1[0.1]$ & $1.6[0.3]$ & $1.2[0.3]$ & $1.2[0.3]$ \\
\hline & $E^{-5} 5_{15}-4_{14}$ & 241.7672 & 20.0 & $1.0[0.1]$ & $1.4[0.3]$ & $1.1[0.2]$ & $1.0[0.2]$ \\
\hline & $E^{-5} 5_{05}-4_{04}$ & 241.7002 & 25.3 & $1.0[0.9]$ & $0.5[0.1]$ & $0.2[0.1]$ & $0.2[0.1]$ \\
\hline
\end{tabular}

Table 3

Observed Complex Molecular Lines with $1 \sigma$ Uncertainties in Brackets

\begin{tabular}{|c|c|c|c|c|c|}
\hline Molecule & Transition & $\begin{array}{c}\text { Frequency } \\
(\mathrm{GHz})\end{array}$ & $\begin{array}{c}E_{\mathrm{low}} \\
\left(\mathrm{cm}^{-1}\right)\end{array}$ & $\begin{array}{l}\text { FWHM }^{\mathrm{a}} \\
\left(\mathrm{km} \mathrm{s}^{-1}\right)\end{array}$ & $\begin{array}{c}\int T d V^{\mathrm{b}} \\
\left(\mathrm{mK} \mathrm{km} \mathrm{s}^{-1}\right)\end{array}$ \\
\hline $\mathrm{HCOOCH}_{3}-\mathrm{E}$ & $7_{16}-7_{15}$ & 88.8432 & 9.5 & $0.55[0.13]$ & $18[4] /<24$ \\
\hline $\mathrm{HCOOCH}_{3}-\mathrm{A}$ & $7_{16}-7_{15}$ & 88.8948 & 9.5 & $0.60[0.12]$ & $16[4] /<24$ \\
\hline $\mathrm{C}_{2} \mathrm{H}_{5} \mathrm{CN}$ & $19_{118}-19_{019}$ & 88.8948 & 55.6 & $\cdots$ & $<11 /<24$ \\
\hline $\mathrm{HOCH}_{2} \mathrm{CHO}$ & $9_{46}-9_{s 7}$ & 88.8924 & 21.2 & $\cdots$ & $<11 /<24$ \\
\hline $\mathrm{CH}_{3} \mathrm{CHO}-\mathrm{A}$ & $6_{25}-5_{24}$ & 115.4939 & 15.9 & $\cdots$ & $<30 /<119$ \\
\hline $\mathrm{C}_{2} \mathrm{H}_{5} \mathrm{OH}$ & $5_{15}-505$ & 115.4945 & 48.2 & $\cdots$ & $<30 /<119$ \\
\hline $\mathrm{CH}_{3} \mathrm{OCH}_{3}$ & $5_{152}-5_{042}$ & 115.5440 & 6.3 & $\cdots$ & $<30 /<119$ \\
\hline $\mathrm{CH}_{3} \mathrm{OCH}_{3}$ & $5_{153}-5_{043}$ & 115.5440 & 6.3 & $\cdots$ & $<30 /<119$ \\
\hline $\mathrm{CH}_{3} \mathrm{OCH}_{3}$ & $5_{151}-5_{041}$ & 115.5448 & 6.3 & $\cdots$ & $<30 /<119$ \\
\hline $\mathrm{CH}_{3} \mathrm{OCH}_{3}$ & $5_{150}-5_{040}$ & 115.5457 & 6.3 & $\cdots$ & $<30 /<119$ \\
\hline $\mathrm{C}_{2} \mathrm{H}_{5} \mathrm{CN}$ & $6_{33}-6_{24}$ & 115.5474 & 9.4 & $\cdots$ & $<30 /<119$ \\
\hline $\mathrm{C}_{2} \mathrm{H}_{5} \mathrm{OH}$ & $4_{322}-4_{232}$ & 130.8715 & 9.3 & $\cdots$ & $<17$ \\
\hline $\mathrm{CH}_{3} \mathrm{CHO}-\mathrm{E}$ & $7_{17}-6_{16}$ & 130.8918 & 14.7 & $0.89[0.18]$ & $39[6]$ \\
\hline $\mathrm{CH}_{3} \mathrm{CHO}-\mathrm{A}$ & $7_{17}-6_{16}$ & 130.8927 & 14.7 & $0.67[0.18]$ & $42[6]$ \\
\hline $\mathrm{C}_{2} \mathrm{H}_{5} \mathrm{CN}$ & $15_{015}-14_{014}$ & 130.9039 & 30.9 & $\cdots$ & $<17$ \\
\hline $\mathrm{CH}_{3} \mathrm{OCH}_{3}$ & $5_{332}-5_{242}$ & 146.8660 & 13.4 & $\cdots$ & $<11 /<26$ \\
\hline $\mathrm{CH}_{3} \mathrm{OCH}_{3}$ & $5_{333}-5_{243}$ & 146.8703 & 13.4 & $\cdots$ & $<11 /<26$ \\
\hline $\mathrm{CH}_{3} \mathrm{OCH}_{3}$ & $5_{331}-5_{241}$ & 146.8725 & 13.4 & $\cdots$ & $<11 /<26$ \\
\hline $\mathrm{CH}_{3} \mathrm{OCH}_{3}$ & $5_{330}-5_{240}$ & 146.8773 & 13.4 & $\cdots$ & $<11 /<26$ \\
\hline $\mathrm{NH}_{2} \mathrm{CHO}$ & $7_{078}-6_{067}$ & 146.8716 & 14.8 & $\cdots$ & $<11 /<26$ \\
\hline $\mathrm{NH}_{2} \mathrm{CHO}$ & $7_{076}-6_{065}$ & 146.8716 & 14.8 & $\cdots$ & $<11 /<26$ \\
\hline $\mathrm{NH}_{2} \mathrm{CHO}$ & $7_{077}-6_{066}$ & 146.8717 & 14.8 & $\cdots$ & $<11 /<26$ \\
\hline $\mathrm{C}_{2} \mathrm{H}_{5} \mathrm{CN}$ & $17_{117}-16_{116}$ & 146.8826 & 40.1 & $\cdots$ & $<11 /<26$ \\
\hline $\mathrm{HCOOCH}_{3}-\mathrm{E}$ & $12_{310}-11_{39}$ & 146.9777 & 31.3 & $\cdots$ & $<9 /<47$ \\
\hline $\mathrm{HCOOCH}_{3}-\mathrm{A}$ & $12_{310}-11_{39}$ & 146.9880 & 31.2 & $\cdots$ & $<9 /<47$ \\
\hline $\mathrm{CH}_{3} \mathrm{OCH}_{3}$ & $7_{172}-6_{062}$ & 147.0242 & 13.2 & $\cdots$ & $<9 /<47$ \\
\hline $\mathrm{CH}_{3} \mathrm{OCH}_{3}$ & $7_{173}-6_{063}$ & 147.0242 & 13.2 & $\cdots$ & $<9 /<47$ \\
\hline $\mathrm{CH}_{3} \mathrm{OCH}_{3}$ & $7_{171}-6_{061}$ & 147.0249 & 13.2 & $\sim 0.53$ & $\sim 8 /<47$ \\
\hline $\mathrm{CH}_{3} \mathrm{OCH}_{3}$ & $7_{170}-6_{060}$ & 147.0256 & 13.2 & $\cdots$ & $<9 /<47$ \\
\hline
\end{tabular}

Notes.

"FWHM for detected lines toward the "core" position.

b Values are for "core"/"outflow" positions. $3 \sigma$ upper limits are calculated from the rms assuming line widths of 0.68 (average of the four complex line detections) and $4.2 \mathrm{~km} \mathrm{~s}^{-1}$ for the "core" and "outflow" positions, respectively.

respectively. All three settings were used toward the core position and two toward the outflow position. Each receiver was connected to a unit of the autocorrelator, with a spectral resolution of $40 \mathrm{MHz}$ and a bandwidth of $120 \mathrm{MHz}$, equivalent to an unsmoothed velocity resolution of $\sim 0.1 \mathrm{~km} \mathrm{~s}^{-1}$. Typical system temperatures were 100-150 K. All observations were carried out using wobbler switching with a $140^{\prime \prime}$ throw $\left(100^{\prime \prime}\right.$ in azimuth and $100^{\prime \prime}$ in elevation).

For both sets of observations, pointing was checked every $\sim 2$ hr on J0316+413 with a typical pointing accuracy of $\sim 2^{\prime \prime}-3^{\prime \prime}$. All intensities reported in this paper are expressed in units of main-beam brightness temperature, which were converted from antenna temperatures in paKo using reported main beam and forward efficiencies ( $\mathrm{B}_{\text {eff }}$ and $\mathrm{F}_{\text {eff }}$ ) of $\sim 75 \%$ and $95 \%$ with the E90 receiver, $\sim 69 \%$ and $93 \%$ with E150 receiver and a mainbeam efficiency of $52 \%$ at $2 \mathrm{~mm}$ for the HERA receiver. The rms in $\mathrm{mK}$ is reported in Table 1.

The data were reduced with the CLASS program, part of the GILDAS software package (see http://www.iram.fr/IRAMFR/ GILDAS). Linear (first-order) baselines were determined from velocity ranges without emission features, and then subtracted from the spectra. Some velocity channels showed spikes, which were replaced by interpolating the closest two good channels in the map, while no correction was made to the complex molecule 


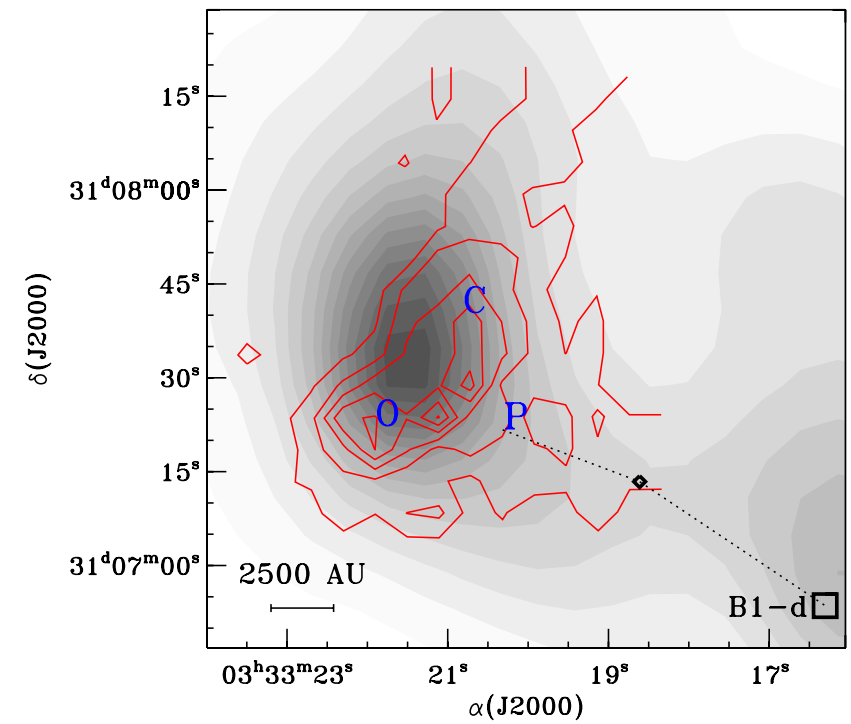

Figure 1. Integrated $\mathrm{CH}_{3} \mathrm{OH}-\mathrm{A}^{+} 5_{05}-4_{01}$ map toward the $\mathrm{B} 1-\mathrm{b}$ region (contours) plotted together with a SCUBA $850 \mu \mathrm{m}$ map (gray scale). The "P" marks the "protostar" position, the "C" the "core" position, and "O" the "outflow" position. The $\mathrm{CH}_{3} \mathrm{OH}$ contours are $\sim 2 \sigma$ i.e., $0.6 \mathrm{~K} \mathrm{~km} \mathrm{~s}^{-1}$. The map also shows the position of nearby protostar B1-d and the main outflow knot between the two protostars (diamond) as well as possible outflow trajectories from either B1-b or B1-d to the knot.

(A color version of this figure is available in the online journal.)

spectra-there were no spikes close to any expected line positions and thus no correction was necessary. The complex organic observation was smoothed to velocity resolutions of $0.4-0.8 \mathrm{~km} \mathrm{~s}^{-1}$ toward the core position and $2-4 \mathrm{~km} \mathrm{~s}^{-1}$ toward the outflow position, respectively, to achieve a maximum signal to noise while still barely resolving the expected lines.

\section{RESULTS \\ 3.1. $\mathrm{CH}_{3} \mathrm{OH}$}

Figure 1 shows the integrated $\mathrm{CH}_{3} \mathrm{OH}$ map superimposed on a SCUBA dust map of the B1-b region. The dust map contains one elongated core, rather than the two sources observed by Hirano et al. (1999). The SCUBA core in the remainder of the paper refers to the dust core in Figure 1, while the "core" position refers to the nearby $\mathrm{CH}_{3} \mathrm{OH}$ maximum probed for complex molecules. The dust and molecular maps share some features, such as the N-S elongation and the "tail" toward the southwest, but the centers of the two maps are offset-the $\mathrm{CH}_{3} \mathrm{OH}$ column density peaks in between the SCUBA core and the "protostar" suggestive of ice desorption on the west side of the dust core due to irradiation from the protostar traveling through outflow cavities, as discussed in more detail below. A velocity channel map of the same $\mathrm{CH}_{3} \mathrm{OH}$ line shows that in addition to the quiescent, elongated $\mathrm{CH}_{3} \mathrm{OH}$ emission that overlaps with the western half of the dust emission, there are at least two highvelocity components, suggestive of two perpendicular outflows which are either directed along the line of sight or which are too young to have any resolved component in the plane of the sky (Figure 2). The two outflow positions are almost coincidental with B1-bS as reported by Hirano et al. (1999) and may thus be evidence for a very young protostellar object embedded in the B1-bS core.

Figure 3 shows the extracted spectra at two of the $\mathrm{CH}_{3} \mathrm{OH}$ intensity peaks in the channel map-the "core" and southeast

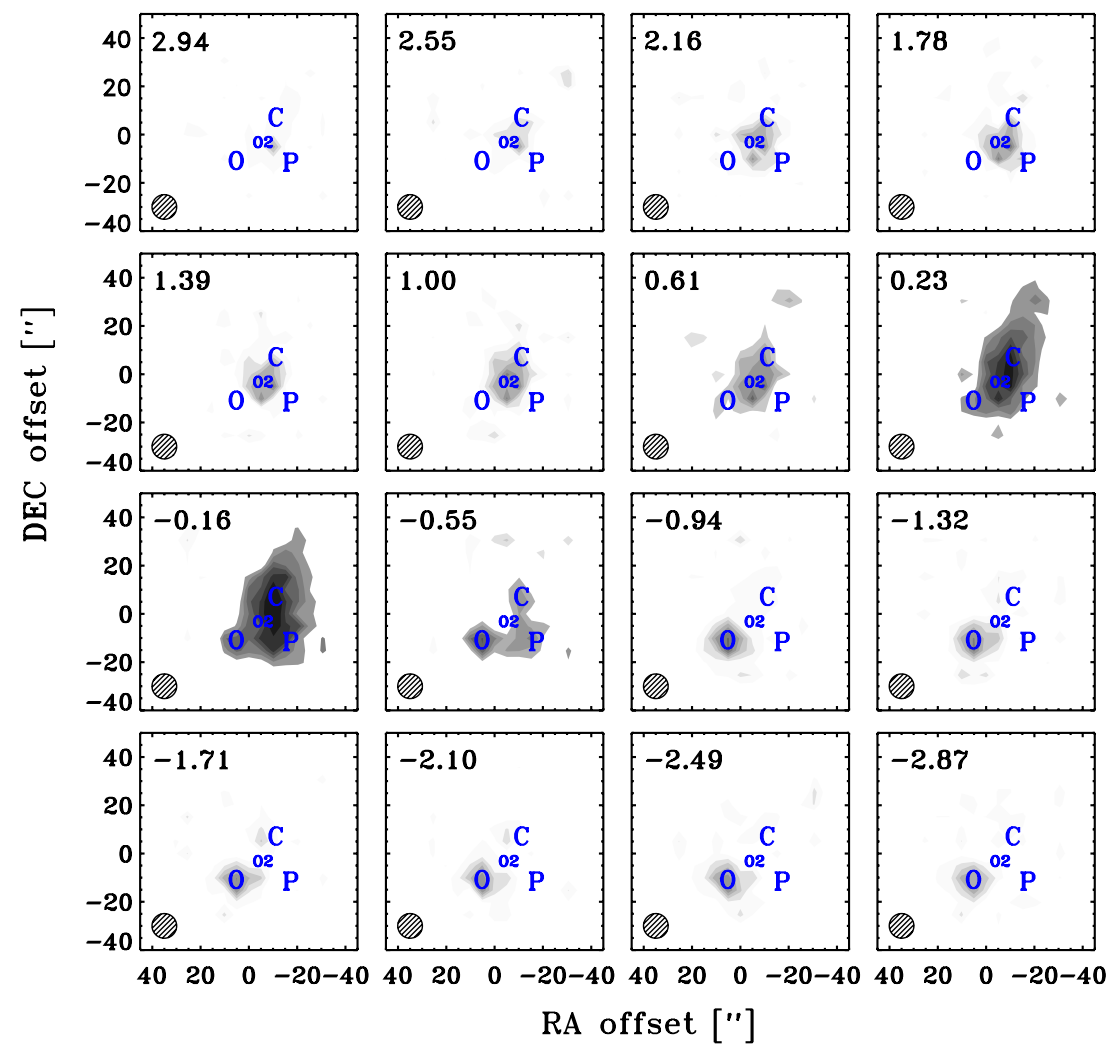

Figure 2. Channel map of the $\mathrm{CH}_{3} \mathrm{OH}-\mathrm{A}^{+} 5_{05}-4_{01}$ line, centered on the B1-b SCUBA dust core. The contours are $\sim 1 \sigma$ i.e., $0.1 \mathrm{~K}$ and the $\mathrm{V}_{\text {lsr }}$ of each channel is listed in the upper left corners. The complex molecule observations were pointed toward the $\mathrm{CH}_{3} \mathrm{OH}$ core $(\mathrm{C})$ seen clearest around $0 \mathrm{~km} \mathrm{~s} \mathrm{~s}^{-1}$ and the southwest outflow $(\mathrm{O})$ visible at $<-0.55 \mathrm{~km} \mathrm{~s}^{-1}$. The second perpendicular outflow is seen in the $>1.0 \mathrm{~km} \mathrm{~s}^{-1}$ channels and is labeled with $\mathrm{O} 2$.

(A color version of this figure is available in the online journal.) 


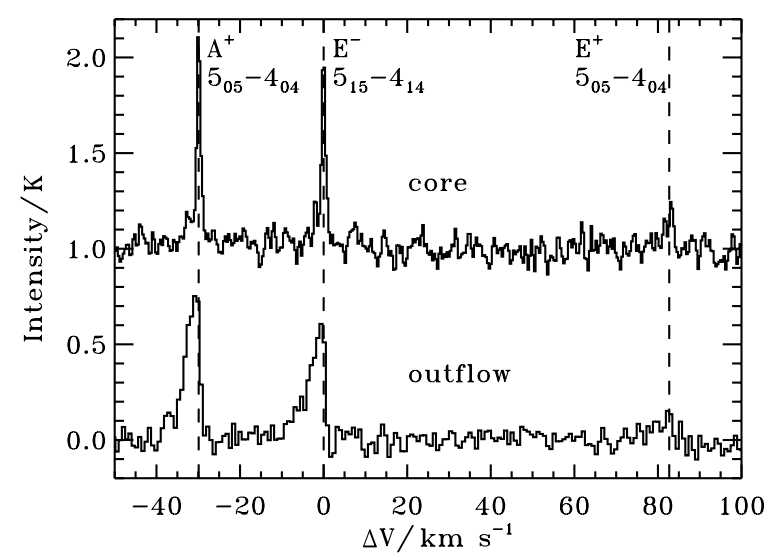

Figure 3. Observed $\mathrm{CH}_{3} \mathrm{OH}$ lines toward the "core" and "outflow" positions corrected by the "core" LSR velocity of $6.3 \mathrm{~km} \mathrm{~s}^{-1}$ and plotted vs. $\Delta \mathrm{V}$, where 0 is the rest frequency $241.7672 \mathrm{GHz}$.

"outflow" positions. The $\mathrm{CH}_{3} \mathrm{OH}$ emission toward the "core" consists of narrow, symmetric lines with small wings. Overall these spectra seem to be dominated by quiescent gas. In contrast the $\mathrm{CH}_{3} \mathrm{OH}$ lines toward the "outflow" position are more than 4 times broader and asymmetric, consistent with the assignment to an outflow. The spectra toward the "core" are similar to those observed by Hiramatsu et al. (2010) toward the same line of sight. They did however not find any evidence for outflow activity toward B1-b. The lack of channel maps in Hiramatsu et al. (2010) prevents direct comparison, but the detected outflows here are on a much smaller scale compared to the outflows they do observe and may thus have been overlooked.

Table 2 lists the observed $\mathrm{CH}_{3} \mathrm{OH}$ transitions as well as the line FWHM and integrated intensities toward the core and outflow positions. To facilitate comparison with observations of complex molecules and previous $\mathrm{CH}_{3} \mathrm{OH}$ observations at lower frequencies, the $\mathrm{CH}_{3} \mathrm{OH}$ intensities were extracted both directly from the HERA maps and from maps convolved with $19^{\prime \prime}$ and $27^{\prime \prime}$ beams, the IRAM $30 \mathrm{~m}$ beam sizes at 131 and 89 $\mathrm{GHz}$, respectively. Because of the asymmetry in the lines, the integrated intensities were calculated by integrating from -10 to $+5 \mathrm{~km} \mathrm{~s}^{-1}$ around each line center, rather than integrating the fitted Gaussians used to estimate the FWHM.

The excitation temperature of $\mathrm{CH}_{3} \mathrm{OH}$ toward each position is estimated using rotational diagrams (Goldsmith \& Langer 1999) in Figure 4 based on the $\mathrm{CH}_{3} \mathrm{OH}$ map intensities convolved with a 27 " beam. The "core" and "outflow" positions only contain three $\mathrm{CH}_{3} \mathrm{OH}$ lines each and the derived temperatures are therefore uncertain by at least a factor of 2 . The best fits result in $10 \mathrm{~K}$ for the "core" and $8 \mathrm{~K}$ for the "outflow." For the "protostar" position, the new data are combined with previous IRAM $30 \mathrm{~m}$ data observed at $\sim 97 \mathrm{GHz}$ (Öberg et al. 2009a). The resulting excitation temperature is $11 \pm 1 \mathrm{~K}$, confirming the estimated rotational temperatures toward the "core" and "outflow." At the densities expected in molecular cloud cores, $\mathrm{CH}_{3} \mathrm{OH}$ is easily sub-thermally excited-rotational temperatures below $25 \mathrm{~K}$ are expected at densities up to $10^{6} \mathrm{~cm}^{-3}$ even if the kinetic temperature is above $100 \mathrm{~K}$ (Bachiller et al. 1998). $\mathrm{NH}_{3}$ maps of the same region however confirm that in this case the kinetic temperature is close to the $\mathrm{CH}_{3} \mathrm{OH}$ rotational temperature, 10-12 K (Bachiller et al. 1990).

\subsection{Search for Complex Molecules}

Building on the $\mathrm{CH}_{3} \mathrm{OH}$ map, we searched for complex molecules toward the "core" and "outflow" positions. All

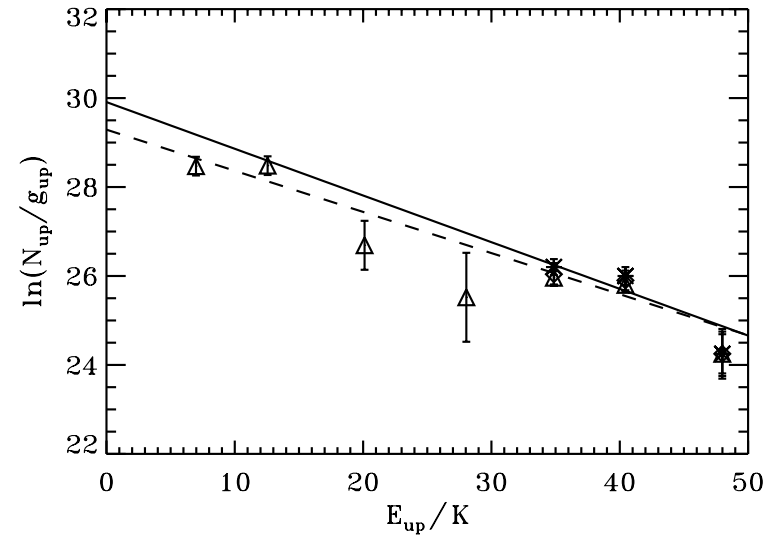

Figure 4. Rotational diagrams of the $\mathrm{CH}_{3} \mathrm{OH}$ abundances derived from the map convolved with a 27 " beam, toward the "core" (diamonds), the "outflow" (stars), and the "protostar" (triangles), including previously published values (Öberg et al. 2009a). The dashed line is fitted to the "protostar" abundances and the solid line to the "core" abundances.

acquired spectra are shown in the Appendix. Figure 5 shows six blowups focusing on the targeted complex molecules. The two lowest lying transitions of $\mathrm{HCOOCH}_{3}\left(E_{\mathrm{up}}=18 \mathrm{~K}\right)$ and of $\mathrm{CH}_{3} \mathrm{CHO}\left(E_{\mathrm{up}}=28 \mathrm{~K}\right)$ are detected toward the core region (Figures 5(a) and (d)) at the $5 \sigma$ level. Higher lying transitions of the two molecules are not detected at the $3 \sigma$ level, nor are any transitions of $\mathrm{C}_{2} \mathrm{H}_{5} \mathrm{OH}, \mathrm{HOCH}_{2} \mathrm{CHO}$, or $\mathrm{C}_{2} \mathrm{H}_{5} \mathrm{CN}$. One $2 \sigma$ transition of $\mathrm{CH}_{3} \mathrm{OCH}_{3}$ is tentatively seen and its intensity is consistent with non-detections of the other lines. No complex molecule lines are detected toward the outflow (Figure 5). The two securely detected species, $\mathrm{HCOOCH}_{3}$ and $\mathrm{CH}_{3} \mathrm{CHO}$, both display narrow line profiles between 0.5 and $0.9 \mathrm{~km} \mathrm{~s}^{-1}$. The $\mathrm{HCOOCH}_{3}$ lines show no evidence of asymmetry, while the $\mathrm{CH}_{3} \mathrm{CHO}$ lines have high-velocity wings suggestive of an emission contribution from the "O2" outflow.

All data for the targeted lines are listed in Table 3, including molecule transitions, catalog frequencies, $E_{\text {low }}$, FWHM of detected lines, integrated intensities for detected lines and integrated intensity upper limits for non-detections. The upper limits on higher lying $\mathrm{HCOOCH}_{3}$ and $\mathrm{CH}_{3} \mathrm{CHO}$ lines are consistent with the $\sim 10 \mathrm{~K}$ excitation temperature of $\mathrm{CH}_{3} \mathrm{OH}$ toward the same line of sight. Thus, a $10 \mathrm{~K}$ excitation temperature is assumed when calculating column densities.

Using these excitation temperatures, the total $\mathrm{HCOOCH}_{3}$ column density $(\mathrm{A}+\mathrm{E})$ toward the $\mathrm{B} 1$-b core is $8.3 \pm 2.8 \times 10^{12}$ $\mathrm{cm}^{-2}$, averaged over the telescope beam, and the total $(\mathrm{A}+\mathrm{E})$ $\mathrm{CH}_{3} \mathrm{CHO}$ column density is $5.4 \pm 1.4 \times 10^{12} \mathrm{~cm}^{-2}$, which corresponds to abundances with respect to $\mathrm{CH}_{3} \mathrm{OH}$ of $2.3 \%$ and $1.1 \%$, respectively. The different beam sizes at different frequencies are accounted for by comparing the $\mathrm{HCOOCH}_{3}$ to the $\mathrm{CH}_{3} \mathrm{OH}$ column density derived with a $27^{\prime \prime}$ beam and the $\mathrm{CH}_{3} \mathrm{CHO}$ to the $\mathrm{CH}_{3} \mathrm{OH}$ column density derived with the $19^{\prime \prime}$ beam. The upper limit abundances for the other molecules are $\lesssim 0.8 \%,<1.0 \%$, and $<1.1 \%$ for $\mathrm{CH}_{3} \mathrm{OCH}_{3}, \mathrm{C}_{2} \mathrm{H}_{5} \mathrm{OH}$, and $\mathrm{HOCH}_{2} \mathrm{CHO}$ toward the core. The most significant upper limit toward the outflow is the total $\mathrm{HCOOCH}_{3}$ abundance of $<1.4 \%$ with respect to $\mathrm{CH}_{3} \mathrm{OH}$. The calculated abundances and upper limits of complex molecules are summarized in Table 4. The lack of detections toward the outflow does not prove that it contains significantly less complex molecules than the "core," but the outflow position is definitely not richer in complex organics than the core region. The outflow upper limits are comparable to the detected abundances toward another low-mass outflow L1157 (Arce et al. 2008) 


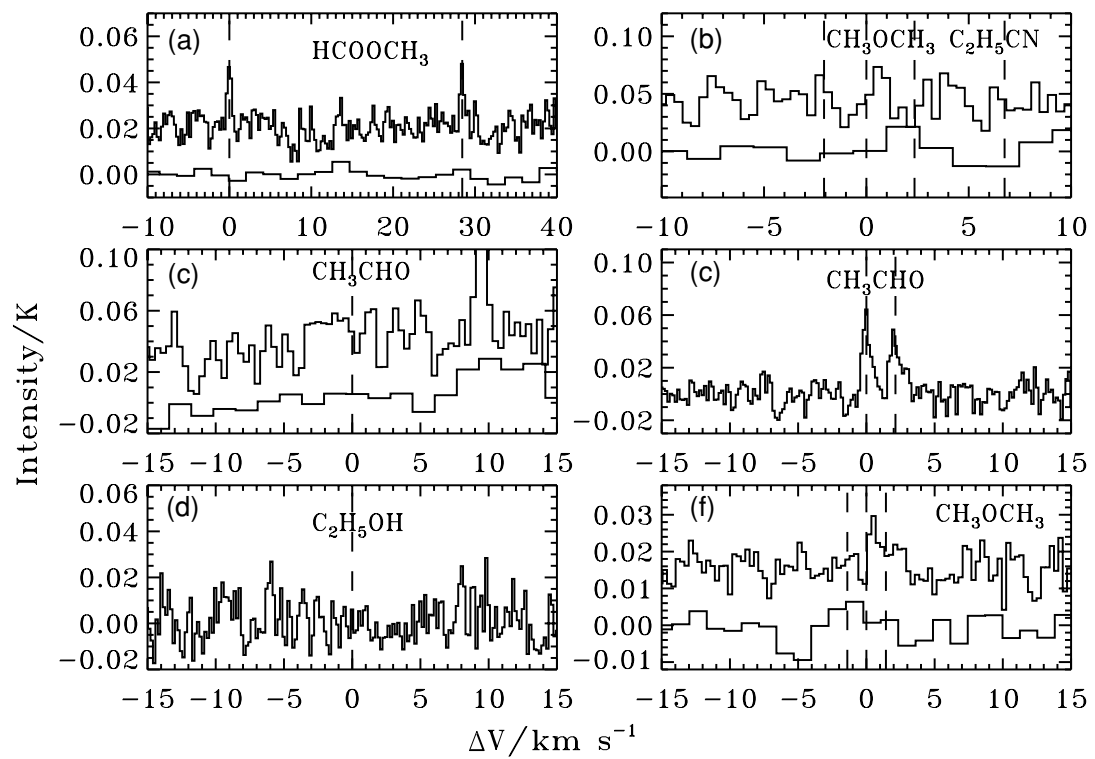

Figure 5. Detected $\mathrm{HCOOCH}_{3}$ and $\mathrm{CH}_{3} \mathrm{CHO}$ lines, a tentative $\mathrm{CH}_{3} \mathrm{OCH}_{3}$ detection in panel (f) and significant non-detections toward the "core" position (upper spectra) and the "outflow" position when observed (lower spectra). The spectra are centered on the rest frequency of (a) $\mathrm{HCOOCH}_{3}-\mathrm{E}_{1}{ }_{6}-7_{15},(\mathrm{~b}) \mathrm{CH}_{3} \mathrm{OCH} \mathrm{CH}_{3}$ $5_{15} 1^{-5} 5_{41}$, (c) $\mathrm{CH}_{3} \mathrm{CHO}-\mathrm{E} 6_{2} 5_{5} 5_{24}$, (d) $\mathrm{CH}_{3} \mathrm{CHO}-\mathrm{E} 7_{17}-6_{16}$, (e) $\mathrm{C}_{2} \mathrm{H}_{5} \mathrm{OH} 4_{32}-4_{23}$, and (f) $\mathrm{CH}_{3} \mathrm{OCH}_{3} 7_{1} 7_{2}-6062$ assuming a systematic velocity of $6.3 \mathrm{~km} \mathrm{~s} \mathrm{~s}^{-1}$. The unmarked line in panel (c) is real and due to NS (see the Appendix).

Table 4

Calculated Abundances and $3 \sigma$ Upper Limits with $1 \sigma$ Uncertainties in Brackets

\begin{tabular}{lcccc}
\hline \hline Position & Species & $T_{\text {rot }} / \mathrm{K}$ & $\mathrm{N}^{\mathrm{a}} / 10^{13}\left(\mathrm{~cm}^{-2}\right)$ & $\% \mathrm{CH}_{3} \mathrm{OH}^{\mathrm{a}}$ \\
\hline "Core" & $\mathrm{CH}_{3} \mathrm{OH}$ & $10[5]$ & $\sim 36 / 47^{\mathrm{b}}$ & 100 \\
"Core" & $\mathrm{HCOOCH}_{3}-\mathrm{E}$ & $\ldots$ & $0.44[0.10]$ & $1.2[0.3]$ \\
"Core" & $\mathrm{HCOOCH}_{3}-\mathrm{A}$ & $\ldots$ & $0.39[0.10]$ & $1.1[0.3]$ \\
"Core" & $\mathrm{CH}_{3} \mathrm{CHO}^{\mathrm{E}}$ & $\ldots$ & $0.26[0.04]$ & $0.6[0.1]$ \\
"Core" & $\mathrm{CH}_{3} \mathrm{CHO}-\mathrm{A}$ & $\ldots$ & $0.28[0.04]$ & $0.6[0.1]$ \\
"Core" & $\mathrm{CH}_{3} \mathrm{OCH} 3$ & $\ldots$ & $\lesssim 0.36$ & $\lesssim 0.8$ \\
"Core" & $\mathrm{C}_{2} \mathrm{H}_{5} \mathrm{OH}$ & $\ldots$ & $<0.48$ & $<1.0$ \\
"Core" & $\mathrm{HCOCH}_{2} \mathrm{OH}$ & $\ldots$ & $<0.41$ & $<1.1$ \\
"Outflow" & $\mathrm{CH}_{3} \mathrm{OH}$ & $8[4]$ & $\sim 78 / 83^{\mathrm{b}}$ & 100 \\
"Outflow" & $\mathrm{HCOOCH}_{3}-\mathrm{E}$ & $\ldots$ & $<0.56$ & $<0.7$ \\
"Outflow" & $\mathrm{HCOOCH}_{3}-\mathrm{A}$ & $\ldots$ & $<0.56$ & $<0.7$ \\
"Protostar" & $\mathrm{CH}_{3} \mathrm{OH}$ & $11[1]$ & $23[4]$ & 100 \\
\hline
\end{tabular}

Notes.

${ }^{a}$ Assuming an excitation temperature of $10 \mathrm{~K}$ for the complex species toward both the core and the outflow position.

b The first value is derived assuming a $27^{\prime \prime}$ beam and the second assuming a $19^{\prime \prime}$ beam.

\section{DISCUSSION}

\subsection{The Origin of the $\mathrm{CH}_{3} \mathrm{OH}$ Gas}

The $\mathrm{CH}_{3} \mathrm{OH}$ average abundance toward the quiescent $\mathrm{CH}_{3} \mathrm{OH}$ "core" is $\sim 2 \times 10^{-9}$ with respect to $N_{\mathrm{H}_{2}}$, assuming a SCUBA dust intensity conversion factor of $N_{\mathrm{H}_{2}} / S_{v}^{\text {beam }}$ of $1.3 \times 10^{20} \mathrm{~cm}^{-2}$ $\left(\mathrm{mJy} \text { beam }{ }^{-1}\right)^{-1}$ (Kauffmann et al. 2008). This abundance is too high to explain with gas-phase formation of $\mathrm{CH}_{3} \mathrm{OH}$ through any mechanism investigated so far, i.e., gas-phase reactions in quiescent cores result in $\mathrm{CH}_{3} \mathrm{OH}$ abundances below $10^{-13}$ (Garrod et al. 2007). The observed $\mathrm{CH}_{3} \mathrm{OH}$ gas is thus a product of ice desorption.

The protostar B1-b belongs to a small set of young lowmass stellar objects with $\mathrm{CH}_{3} \mathrm{OH}$ ice abundances of $>10 \%$ with respect to $\mathrm{H}_{2} \mathrm{O}$ (Boogert et al. 2008, Bottinelli et al. 2010). $\mathrm{CH}_{3} \mathrm{OH}$ ice has been previously observed to vary on small scales, however, and the ice abundance toward the "core" and "outflow" may be as low as $1 \%$ with respect to $\mathrm{H}_{2} \mathrm{O}$ ice. Still, $<0.5 \%$ of the $\mathrm{CH}_{3} \mathrm{OH}$ ice must evaporate to account for the observed $\mathrm{CH}_{3} \mathrm{OH}$ abundance of $\sim 2 \times 10^{-9}$ toward the "core," assuming an $\mathrm{H}_{2} \mathrm{O}$ abundance of $\sim 5 \times 10^{-5}$ with respect to $\mathrm{H}_{2}$.

The extent of the $\mathrm{CH}_{3} \mathrm{OH}$ gas $(\sim 10,000 \times 15,000 \mathrm{AU})$ together with the low excitation temperature of $\mathrm{CH}_{3} \mathrm{OH}$ and the offset between the $\mathrm{CH}_{3} \mathrm{OH}$ "core" and the "protostar" exclude thermal ice evaporation as a major contributor to the observed abundances - a low-mass protostar cannot heat more than a few $100 \mathrm{AU}$ to the sublimation temperature of $\mathrm{CH}_{3} \mathrm{OH}$ of $\sim 80 \mathrm{~K}$. This leaves non-thermal evaporation of ices, which can be broadly divided into two categories: ice evaporation due to grain sputtering in shocks and less violent non-thermal ice evaporation due to UV irradiation, cosmic rays or release of chemical energy (Jones et al. 1996; Shen et al. 2004; Garrod et al. 2007). Grain sputtering is often invoked to explain excess $\mathrm{CH}_{3} \mathrm{OH}$ in protostellar outflows (e.g., Bachiller et al. 2001) and is probably responsible for the factor of a few higher abundances of $\mathrm{CH}_{3} \mathrm{OH}$ gas in the two outflow positions around the dust core, using the same conversion factor as above to derive the dust column densities from the SCUBA map. The narrow $\mathrm{CH}_{3} \mathrm{OH}$ lines in the remainder of the map suggest a different origin for the gas toward the protostar and "core" regions.

The asymmetric distribution of $\mathrm{CH}_{3} \mathrm{OH}$ compared to the dust core further suggest that ice is desorbed by irradiation from the direction of the protostar, illuminating the southwest side of the core. The exact nature of the irradiation is difficult to constrain without detailed modeling, but UV photodesorption is known to be efficient (Öberg et al. 2009b). The dust core has a visual extinction of $>100$ mag. For radiation to affect the "core" region thus requires extensive cavities in the interstellar medium. As discussed in the Introduction, there are several large-scale outflows crossing the B1 region, which could have carved out such cavities (Jørgensen et al. 2006; Walawender et al. 2009). In particular, Figure 1 shows that there is a visible outflow in the "right" direction originating either from the B1-b protostar or from the nearby B1-d protostar to the southwest. In either case, the outflow may continue on toward the "core," hidden from observations by the large column of dust, resulting in UV 


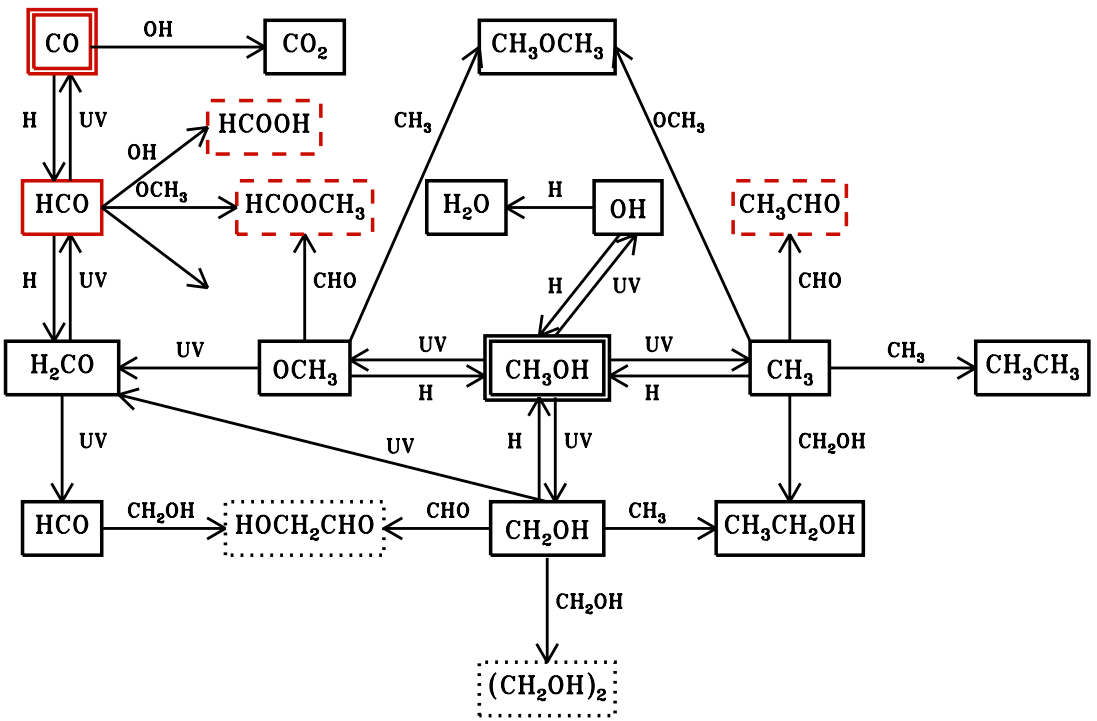

Figure 6. Reaction scheme of a $\mathrm{CH}_{3} \mathrm{OH}$-based ice photochemistry adapted from Öberg et al. (2009b) to highlight the impact of CO. In a CO-dominated ice the production of several HCO-bearing complex species (red dashed boxes) is enhanced relative to molecules such as $\mathrm{C}_{2} \mathrm{H}_{5} \mathrm{OH}, \mathrm{CH}_{3} \mathrm{OCH} \mathrm{OH}_{3}$, and $\left(\mathrm{CH}_{2} \mathrm{OH}\right)_{2}$, which tend to dominate among the pure $\mathrm{CH}_{3} \mathrm{OH}$-photochemistry products (solid and dotted boxes). $\left(\mathrm{CH}_{2} \mathrm{OH}\right)_{2}$ and $\mathrm{HOCH}_{2} \mathrm{CHO}$ (dotted boxes) are only produced abundantly at lukewarm temperatures ( $>30 \mathrm{~K}$ in the laboratory).

(A color version of this figure is available in the online journal.)

irradiation of the icy grains on the side of the dust core closest to the protostar.

UV irradiation can be generated in a number of ways within such an outflow cavity. If an outflow is still active in the direction of the "core" position, the UV radiation may originate in the jet shock itself (Reipurth \& Bally 2001). Some outflows are also known to become hot enough to emit X-rays (Pravdo et al. 2001), which may directly desorb the ice or desorb it through secondary UV photons. The narrow line width of the $\mathrm{CH}_{3} \mathrm{OH}$ emission suggests however that the $\mathrm{CH}_{3} \mathrm{OH}$ gas does not originate close to shocked gas. It seems more likely that a past outflow has opened a cavity between the protostar and the "core" position and that UV radiation from this neighboring low-mass protostar is desorbing the ices. Low-mass protostars are known to have excess UV fluxes compared to the interstellar radiation field, originating in the boundary layer between the protostar and the accretion disk (Spaans et al. 1995).

UV photodesorption is thus a probable source of the $\mathrm{CH}_{3} \mathrm{OH}$ gas distribution toward the B1-b dust core. Observations of UV tracers are however needed to confirm this scenario, since we cannot completely rule out that the $\mathrm{CH}_{3} \mathrm{OH}$ is the leftovers from grain sputtering by the same shock that opened up the cavity, if it passed through the area $10^{4}-10^{5}$ years ago, the typical depletion timescale at molecular cloud densities.

\subsection{The Origin of Complex Molecules Toward B1-b}

The similar line widths and excitation temperature upper limits of $\mathrm{HCOOCH}_{3}$ and $\mathrm{CH}_{3} \mathrm{CHO}$ compared to $\mathrm{CH}_{3} \mathrm{OH}$ suggest that the complex molecules toward the $\mathrm{B} 1-\mathrm{b}$ core originate from photodesorbed ice as well. This is a new potential source of complex organic molecules around low-mass protostars compared to what has been previously suggested in the literature, where complex molecules have been observed in a small warm core or disk where ices have evaporated thermally (e.g., Bottinelli et al. 2007; Jørgensen et al. 2005) or in shocks following grain sputtering (e.g., Arce et al. 2008). Contrary to sputtering and thermal desorption, which quickly destroys the entire ice mantle in a small region, UV photodesorption can release a small fraction of the ice over large quiescent regions. This offers the opportunity to study ice chemistry in situ as it evolves around protostars, as previously suggested in Öberg et al. (2009a, 2009b).

Non-thermal desorption of $\mathrm{HCOOCH}_{3}$ and $\mathrm{CH}_{3} \mathrm{CHO}$ is only a probable source of the observed gas if the molecules can be produced efficiently on grains, however. As discussed in the Introduction, such a production channel exists. UV processing of $\mathrm{CO}: \mathrm{CH}_{3} \mathrm{OH}$-rich ices produces complex molecules at abundances that are consistent with the observed abundances of a few \% with respect to $\mathrm{CH}_{3} \mathrm{OH}$.

Moreover this formation path explains the relative abundances of $\mathrm{HCOOCH}_{3}$ and $\mathrm{CH}_{3} \mathrm{OCH}_{3}$, or $\mathrm{C}_{2} \mathrm{H}_{5} \mathrm{OH}$. Figure 6 illustrates how the addition of $\mathrm{CO}$ affects the complex $\mathrm{CH}_{3} \mathrm{OH}$ chemistry to produce the observed molecules. Quantitatively, UV irradiation of a $\mathrm{CH}_{3} \mathrm{OH}: \mathrm{CO} 1: 10$ ice mixture at $20 \mathrm{~K}$ under laboratory conditions results in the production of a $\mathrm{CH}_{3} \mathrm{OCH}_{3} / \mathrm{HCOOCH}_{3}$ ratio of $<0.1$ and irradiation of a pure $\mathrm{CH}_{3} \mathrm{OH}$ ice in $\mathrm{CH}_{3} \mathrm{OCH}_{3} / \mathrm{HCOOCH}_{3}$ ratios of $>1.3$. While the laboratory results cannot be directly extrapolated to $\mathrm{B} 1-\mathrm{b}$, a $\mathrm{CO}$-rich ice is certainly needed to produce the observed low $\mathrm{CH}_{3} \mathrm{OCH}_{3}\left(\mathrm{C}_{2} \mathrm{H}_{5} \mathrm{OH}\right) / \mathrm{HCOOCH}_{3}$ ratios; without $\mathrm{CO}$ in the ice, the most recent model predicts ratios of $>10$, rather than the observed $<0.5$ (Garrod et al. 2008).

\subsection{Comparison with Previous Complex Chemistry Observations}

With energetic $\mathrm{CO}: \mathrm{CH}_{3} \mathrm{OH}$ ice processing followed by nonthermal desorption established as the most probable explanation for the observed complex molecules in B1-b, it is interesting to see how the chemistry toward B1-b compares with complex chemistry observations toward other low-mass sources: NGC1333-IRAS 2A, 4A, and 4B, IRAS 16293-2422, and L1157. All sources have been observed with single-dish telescopes where the emission region is assumed to be unresolved. These observations thus contain emission from both hot and cold material-dependent on the density profile one or the other component may dominate. In addition IRAS 16293-2422 has been studied extensively using interferometry. In these 
(a) Early ice formation

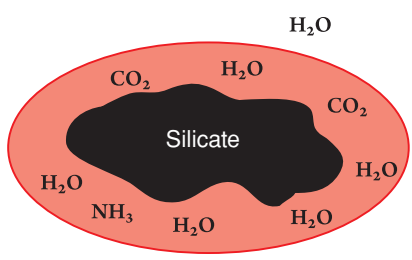

(b) Cloud core ice formation

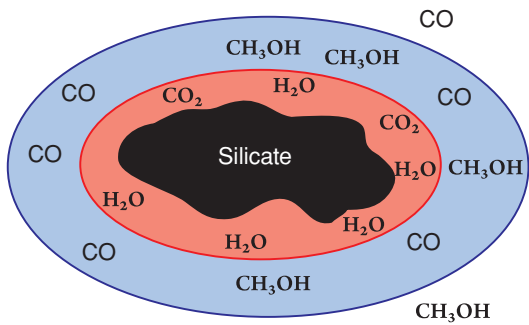

(c) Cold ( $<20 \mathrm{~K})$ UV_processing

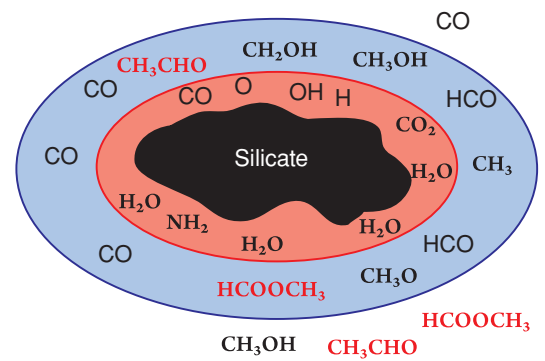

(d) Lukewarm protostellar envelope $>20 \mathrm{~K}$

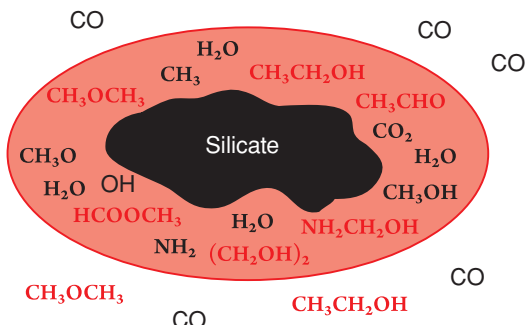

(e) Protostellar hot core $>100 \mathrm{~K}$

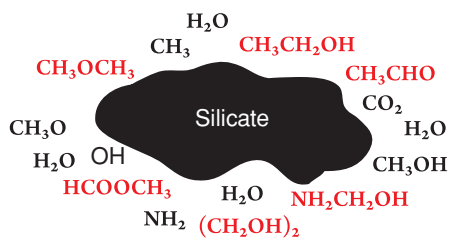

Figure 7. Suggested evolution of ices during star formation. Pink indicates an $\mathrm{H}_{2} \mathrm{O}$-dominated ice and blue a CO-dominated ice. At each cold stage a small amount of the ice is released non-thermally. Early during cloud formation (a) an $\mathrm{H}_{2} \mathrm{O}$-rich ice forms. Once a critical density and temperature is reached $\mathrm{CO}$ freezes out catastrophically (b), providing reactants for $\mathrm{CH}_{3} \mathrm{OH}$ ice formation. Far away from the protostar (c), photoprocessing of the CO-rich ice results in the production of, e.g., $\mathrm{HCOOCH}_{3}$. Closer to the protostar (d), following sublimation of $\mathrm{CO}$, other complex molecules become abundant. Finally, all ice desorb thermally close to the protostar $>100 \mathrm{~K}(\mathrm{e})$.

(A color version of this figure is available in the online journal.)

Table 5

Ratios of Complex Species Toward Different Low-mass Sources

\begin{tabular}{lccccc}
\hline \hline \multicolumn{1}{c}{ Source } & $\begin{array}{c}T_{\text {rot }} \\
(\mathrm{K})\end{array}$ & $\begin{array}{c}\mathrm{FWHM} \\
\left(\mathrm{km} \mathrm{s}^{-1}\right)\end{array}$ & $\begin{array}{c}\mathrm{CH}_{3} \mathrm{CHO} / \\
\mathrm{HCOOCH}_{3}{ }^{\mathrm{a}}\end{array}$ & $\begin{array}{c}\mathrm{CH}_{3} \mathrm{OCH}_{3} / \\
\mathrm{HCOOCH}_{3}{ }^{\mathrm{a}}\end{array}$ & $\begin{array}{c}\mathrm{C}_{2} \mathrm{H}_{5} \mathrm{OH} / \\
\mathrm{HCOOCH}_{3}{ }^{\mathrm{a}}\end{array}$ \\
\hline B1-b core & $10[10]$ & $0.55-0.89$ & $0.5[0.3]$ & $\lesssim 0.3$ & $<0.4$ \\
IRAS 16293 env. $^{\mathrm{b}}$ & $14-67$ & $0.8-10$ & 0.1 & 0.67 & $\ldots$ \\
IRAS 16293 core A/B $^{\mathrm{c}}$ & $100-300$ & $1.5-2.5$ & $<0.1 / 3$ & $1 / 2$ & $2 / 1$ \\
NGC1333 IRAS 2A $^{\mathrm{d}, \mathrm{e}}$ & $38-101$ & $1-4$ & $\ldots$ & $<0.3$ & $\ldots$ \\
NGC1333 IRAS 4A $^{\mathrm{d}}$ & $24-36$ & $1.2-4.2$ & $\ldots$ & $<0.4$ & $\ldots$ \\
NGC1333 IRAS 4B $^{\mathrm{d}}$ & $34-38$ & $0.5-1.8$ & $\cdots$ & $\cdots$ & 0.4 \\
L1157 outflow $^{\mathrm{f}}$ & $18-27$ & $2.3-5.5$ & $\cdots$ & $\ldots$ & $\ldots$ \\
\hline
\end{tabular}

Notes.

${ }^{a}$ Where only A or $\mathrm{E}$ column densities are available the total $\mathrm{HCOOCH}_{3}$ abundance is derived by assuming equal abundances of both.

${ }^{\mathrm{b}}$ Cazaux et al. (2003) and Herbst \& van Dishoeck (2009).

${ }^{c}$ Beam size of 5".5 × 3".2 Bisschop et al. (2008), 1".3 × 2".7 Kuan et al. (2004), and Huang et al. (2005).

${ }^{d}$ Abundances are rescaled assuming the same beam dilution for $\mathrm{CH}_{3} \mathrm{OH}$ and complex organic molecules. Single-dish column densities from Maret et al. (2005), and Bottinelli et al. (2004, 2007).

${ }^{\mathrm{e}} \mathrm{CH}_{3} \mathrm{OCH}_{3}$ is detected toward the central core using the Submillimeter Array (Jørgensen et al. 2005).

${ }^{\mathrm{f}}$ Arce et al. (2008).

observations two cores, $\mathrm{A}$ and $\mathrm{B}$, are resolved and emission from the cold envelope can be excluded.

Because of assumptions on the emitting region for complex molecules in most previous studies, comparisons of absolute abundances are difficult between different sources using literature values. Assuming the same source sizes of $\mathrm{CH}_{3} \mathrm{OH}$ and complex molecules toward protostars observed with single-dish telescopes result in abundances of a few percent with respect to $\mathrm{CH}_{3} \mathrm{OH}$, comparable to those observed toward B1-b (Maret et al. 2005; Bottinelli et al. 2004, 2007). Where beam averaged or resolved values of complex molecule abundances are actually reported, e.g., toward the low-mass outflow L1157 and the hot cores (or accretion disks) of the two IRAS 16293-2422 cores, the abundances are also of the order of a few percent (Bisschop et al. 2008; Arce et al. 2008). There is thus no evidence that the complex molecule abundances with respect to $\mathrm{CH}_{3} \mathrm{OH}$ toward B1-b are special compared to other low-mass sources, ranging from outflows to hot cores.

Table 5 lists the abundance ratios of different complex molecules toward the different low-mass sources. The B1-b $\mathrm{CH}_{3} \mathrm{CHO} / \mathrm{HCOOCH}_{3}$ ratio falls in between what has been previously measured toward the $\mathrm{A}$ and $\mathrm{B}$ cores in IRAS 16293. The upper limits on the $\mathrm{CH}_{3} \mathrm{OCH}_{3} / \mathrm{HCOOCH}_{3}$ and $\mathrm{C}_{2} \mathrm{H}_{5} \mathrm{OH} / \mathrm{HCOOCH}_{3}$ ratios are comparable to the single-dish observations toward NGC1333 2A, 4A, and 4B, and possibly toward the IRAS 16293 envelope as well, but significantly lower compared to the resolved observations toward the IRAS $16293 \mathrm{~A}$ and B cores. In resolved observations toward NGC $13332 \mathrm{~A}$ there is also a $\mathrm{CH}_{3} \mathrm{OCH}_{3}$ detection pointing to a higher $\mathrm{CH}_{3} \mathrm{OCH}_{3}$ to $\mathrm{HCOOCH}_{3}$ ratio in the warm region 
close to the protostar (Jørgensen et al. 2005). This is entirely consistent with a scenario where complex molecules form in cold $\mathrm{CO}: \mathrm{CH}_{3} \mathrm{OH}$ ice mixtures in the outer envelope, followed by further formation of $\mathrm{CH}_{3} \mathrm{OHCH}_{3}$ and $\mathrm{C}_{2} \mathrm{H}_{5} \mathrm{OH}$ in the warmer CO-depleted $\mathrm{CH}_{3} \mathrm{OH}$ ice close to the protostar (Figure 7). In the cold parts, complex ices are only released non-thermally through, e.g., UV photodesorption, while closer to the protostar thermal desorption is likely to dominate. This agrees with the low excitation temperatures in the single-dish observations compared to the observations that resolve the innermost part of the envelope.

\section{CONCLUSIONS}

1. Cold $\mathrm{CH}_{3} \mathrm{OH}$ gas (excitation temperature of $\sim 10 \mathrm{~K}$ ) is abundant and widespread toward B1-b. Quiescent $\mathrm{CH}_{3} \mathrm{OH}$ is most abundant in between the B1-b SCUBA dust core and the B1-b protostar, indicative of UV photodesorption of ice on the side of the quiescent dust core because of radiation from the protostar escaping through outflow cavities.

2. Cold $\mathrm{HCOOCH}_{3}$ and $\mathrm{CH}_{3} \mathrm{CHO}$ are both detected and $\mathrm{CH}_{3} \mathrm{OCH}_{3}$ is tentatively detected toward the quiescent $\mathrm{CH}_{3} \mathrm{OH}$ peak. No complex molecules are observed toward an outflow associated with B1-b, but $3 \sigma$ upper limits with respect to $\mathrm{CH}_{3} \mathrm{OH}$ are only slightly lower compared to the quiescent core. In addition, an asymmetry in the $\mathrm{CH}_{3} \mathrm{CHO}$ emission lines is suggestive of some contribution from a small outflow included in the beam.

3. Assuming a $10 \mathrm{~K}$ excitation temperature the calculated beam-averaged abundances are $2.3 \%$ for $\mathrm{HCOOCH}_{3}, 1.1 \%$ for $\mathrm{CH}_{3} \mathrm{CHO}, \lesssim 0.8 \%$ for $\mathrm{CH}_{3} \mathrm{OCH}_{3}$, and $<1.0-1.1 \%$ for $\mathrm{C}_{2} \mathrm{H}_{5} \mathrm{OH}$ and $\mathrm{HOCH}_{2} \mathrm{CHO}$ with respect to $\mathrm{CH}_{3} \mathrm{OH}$.

4. Building on recent experiments, the observations of large abundances of HCO-containing molecules are explained by $\mathrm{UV} /$ cosmic ray processing of cold $\mathrm{CH}_{3} \mathrm{OH}$ : $\mathrm{CO}$ ice followed by non-thermal desorption of a fraction of the produced organic ice.

5. The beam-averaged abundances with respect to $\mathrm{CH}_{3} \mathrm{OH}$ and the ratios between different complex molecules are similar to other single-dish observations toward low-mass protostars. In contrast, resolved observations of the cores around protostars are more abundant in complex molecules without an HCO group. This is consistent with a complex ice chemistry that evolves from $\mathrm{HCO}$ rich to $\mathrm{HCO}$ poor as the ice warms up and the $\mathrm{CO}-$ ice evaporates when the icy dust falls toward the protostar.

Including B1-b, there are still only a handful of observations of complex molecules toward low-mass protostars. In addition, few complex molecules are detected toward each source. This makes it difficult both to determine the prevalence of a complex organic chemistry around low-mass protostars and to firmly establish the main formation path of such molecules. The detections of complex molecules in the vicinity of the $\mathrm{CH}_{3} \mathrm{OH}-$ ice-rich protostar suggest that targeting other $\mathrm{CH}_{3} \mathrm{OH}$-ice rich protostars may increase our sample of complex molecule detections significantly. Maybe more important from a formation pathway point of view is to increase our understanding on how the complex chemistry varies between warm, lukewarm, and cold regions i.e., how it varies with distance from the protostar. This should be pursued both on larger scales with single-dish observations and on smaller scales with interferometers-similarly to what has been done toward IRAS 16293 and NGC1333 2a (e.g., Jørgensen et al. 2005; Bisschop et al. 2008). In the

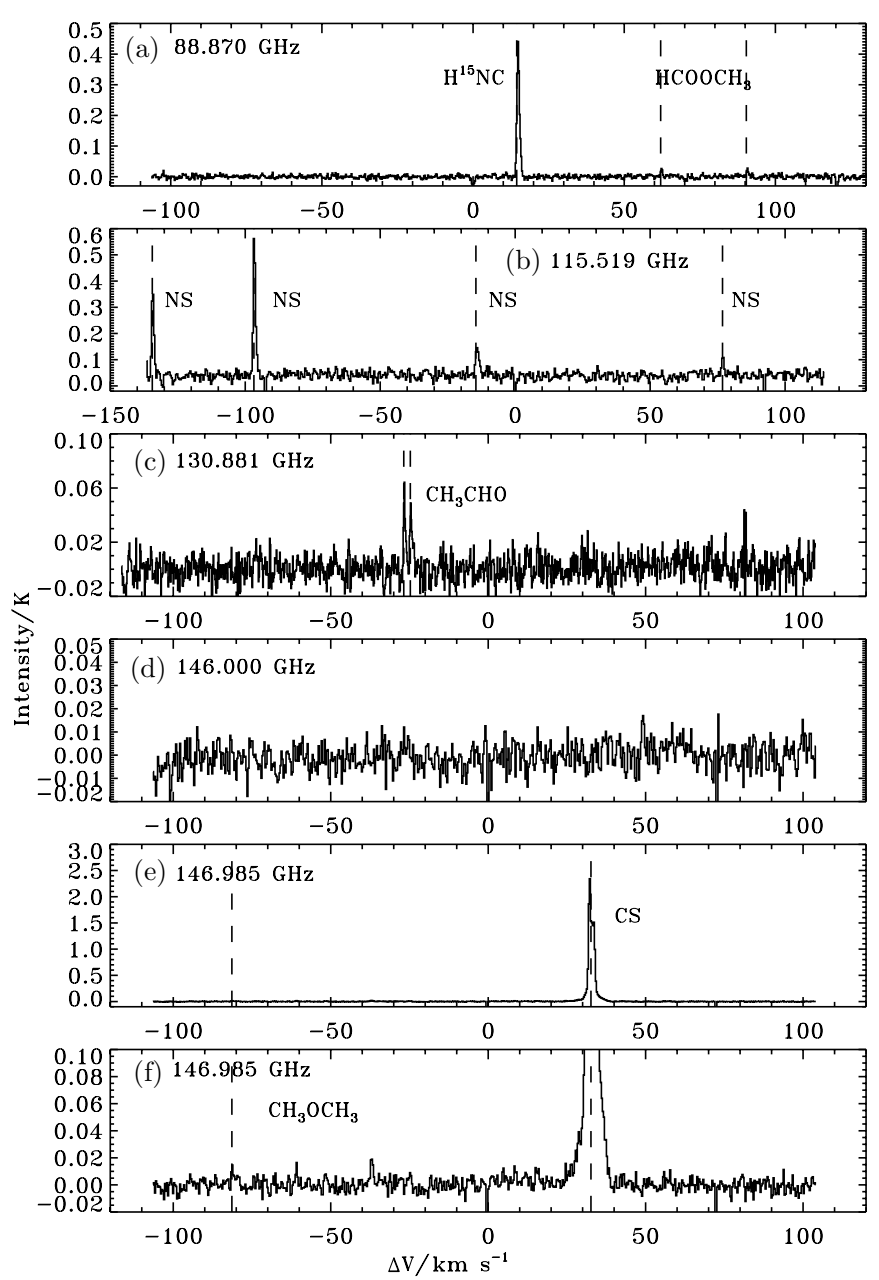

Figure 8. Observed lines in the five different settings explored toward the "core" position plotted vs. $\Delta \mathrm{V}$, the deviation from the core velocity $6.3 \mathrm{~km} \mathrm{~s}^{-1}$. The spectra are centered on the rest frequency shown in each panel.

meantime the complex molecules observed toward B1-b, and their exceptionally low excitation temperatures and line widths, provide clear evidence for the efficient formation of complex ices during star and planet formation.

We are grateful to the IRAM staff for help with the observations and reduction of the resulting data. This work has benefitted from discussions with Herma Cuppen, Robin Garrod, and Lars Kristensen, and from comments by an anonymous referee. Umut Yildiz carried out the second round of observations at the IRAM 30 m with the financial support of RadioNet. Support for K.I.Ö is provided by NASA through Hubble Fellowship grant awarded by the Space Telescope Science Institute, which is operated by the Association of Universities for Research in Astronomy, Inc., for NASA, under contract NAS 5-26555. Astrochemistry in Leiden is supported by an SPINOZA grant of the Netherlands Organization for Scientific Research (NWO). The Centre for Star and Planet Formation is funded by the Danish National Research Foundation and the University of Copenhagen's programme of excellence.

\section{APPENDIX}

\section{COMPLETE SPECTRA FOR ALL SETTINGS}

Complete spectra for all settings are shown in Figure 8 and 9. 

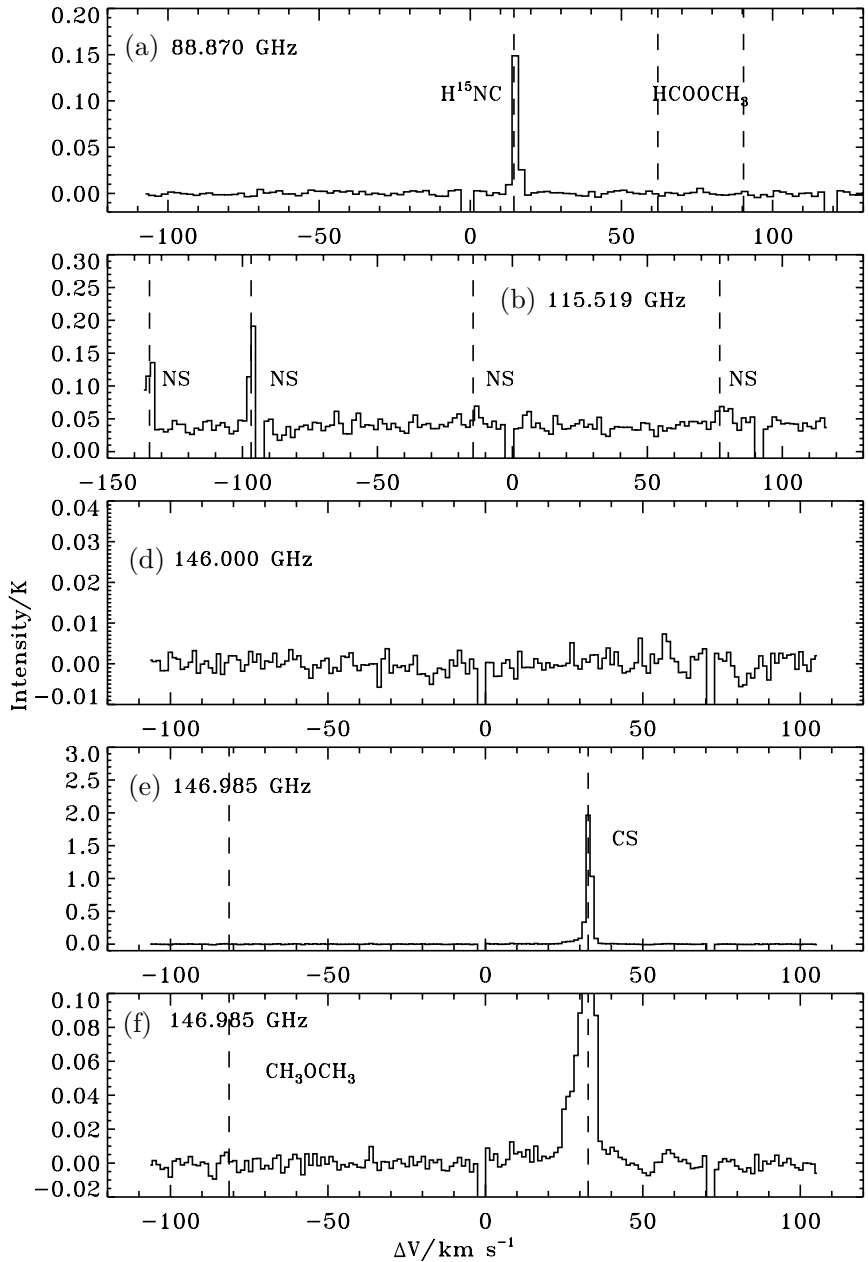

Figure 9. Observed lines in the five different settings explored toward the "outflow" position plotted vs. $\Delta \mathrm{V}$, the deviation from the core velocity $6.3 \mathrm{~km} \mathrm{~s}^{-1}$. The spectra are centered on the rest frequency shown in each panel.

\section{REFERENCES}

Arce, H. G., Santiago-García, J., Jørgensen, J. K., Tafalla, M., \& Bachiller, R. 2008, ApJ, 681, L21

Bachiller, R., Codella, C., Colomer, F., Liechti, S., \& Walmsley, C. M. 1998, A\&A, 335, 266
Bachiller, R., Menten, K. M., \& del Rio Alvarez, S. 1990, A\&A, 236, 461

Bachiller, R., Perez-Gutierrez, M., Kumar, M. S. N., \& Tafalla, M. 2001, A\&A, 372, 899

Bennett, C. J., \& Kaiser, R. I. 2007, ApJ, 661, 899

Bisschop, S. E., Fraser, H. J., Öberg, K. I., van Dishoeck, E. F., \& Schlemmer, S. 2006, A\&A, 449, 1297

Bisschop, S. E., Jørgensen, J. K., Bourke, T. L., Bottinelli, S., \& van Dishoeck, E. F. 2008 , A\&A, 488, 959

Boogert, A. C. A., et al. 2008, ApJ, 678, 985

Bottinelli, S., Ceccarelli, C., Williams, J. P., \& Lefloch, B. 2007, A\&A, 463, 601

Bottinelli, S., et al. 2004, ApJ, 615, 354

Bottinelli, S., et al. 2010, A\&A, in press

Cazaux, S., et al. 2003, ApJ, 593, L51

Charnley, S. B., Tielens, A. G. G. M., \& Millar, T. J. 1992, ApJ, 399, L71

Cuppen, H. M., van Dishoeck, E. F., Herbst, E., \& Tielens, A. G. G. M. 2009, A\&A, 508, 275

Garrod, R. T., \& Herbst, E. 2006, A\&A, 457, 927

Garrod, R. T., Wakelam, V., \& Herbst, E. 2007, A\&A, 467, 1103

Garrod, R. T., Weaver, S. L. W., \& Herbst, E. 2008, ApJ, 682, 283

Goldsmith, P. F., \& Langer, W. D. 1999, ApJ, 517, 209

Herbst, E., \& van Dishoeck, E. F. 2009, ARA\&A, 47, 427

Hiramatsu, M., Hirano, N., \& Takakuwa, S. 2010, ApJ, 712, 778

Hirano, N., Kamazaki, T., Mikami, H., Ohashi, N., \& Umemoto, T. 1999, in Proc. Star Formation 1999, ed. T. Nakamoto (Nagoya: Nobeyama Radio Observatory), 181

Huang, H.-C., et al. 2005, Adv. Space Res., 36, 146

Jones, A. P., Tielens, A. G. G. M., \& Hollenbach, D. J. 1996, ApJ, 469, 740

Jørgensen, J. K., et al. 2005, ApJ, 632, 973

Jørgensen, J. K., et al. 2006, ApJ, 645, 1246

Kauffmann, J., Bertoldi, F., Bourke, T. L., Evans, N. J., II., \& Lee, C. W. 2008, A\&A, 487, 993

Kuan, Y., et al. 2004, ApJ, 616, L27

Maret, S., et al. 2005, A\&A, 442, 527

Müller, H. S. P., Thorwirth, S., Roth, D. A., \& Winnewisser, G. 2001, A\&A, 370, L49

Nomura, H., \& Millar, T. J. 2004, A\&A, 414, 409

Öberg, K. I., Bottinelli, S., \& van Dishoeck, E. F. 2009a, A\&A, 494, L13

Öberg, K. I., Garrod, R. T., van Dishoeck, E. F., \& Linnartz, H. 2009b, A\&A, 504, 891

Pravdo, S. H., et al. 2001, Nature, 413, 708

Reipurth, B., \& Bally, J. 2001, ARA\&A, 39, 403

Schuster, K., et al. 2004, A\&A, 423, 1171

Shen, C. J., Greenberg, J. M., Schutte, W. A., \& van Dishoeck, E. F. 2004, A\&A, 415, 203

Spaans, M., Hogerheijde, M. R., Mundy, L. G., \& van Dishoeck, E. F. 1995, ApJ, 455, L167

van Dishoeck, E. F., Blake, G. A., Jansen, D. J., \& Groesbeck, T. D. 1995, ApJ, 447,760

Walawender, J., Reipurth, B., \& Bally, J. 2009, AJ, 137, 3254

Watanabe, N., Shiraki, T., \& Kouchi, A. 2003, ApJ, 588, L121 